\title{
Luta e resistência: dimensões para a promoção de saúde Mbya Guarani
}

\author{
Flaviana Sousa* \\ Ramiro Gonzalez (1) \\ Danilo Guimarães (1) \\ Universidade de São Paulo. São Paulo, SP, Brasil
}

\begin{abstract}
Resumo: Esse artigo discute como a luta indígena do povo Mbya Guarani pode ser compreendida como uma dimensão necessária para o estudo da promoção de saúde; luta que se dá em uma situação em que as comunidades manifestam a vivência de uma série de conflitos denunciados, como desrespeito do Estado brasileiro aos seus direitos constitucionais. Realizamos uma análise dialógica de discursos de lideranças Mbya Guarani, presentes em noticiários produzidos por coletivos indígenas e no documentário "Teko Rexaĩ: Saúde Guarani Mbyá". Discutimos as tensões entre a concepção Guarani de Teko Porã e o que está previsto pelo Subsistema de Atenção à Saúde Indígena. Argumentamos que as concepções de saúde e de cuidado, desde o enfoque do construtivismo semiótico-cultural em psicologia e suas interfaces com a reflexão ética, devem considerar o ethos indígena. Isso permite repensar o papel dos agentes de saúde em relação aos problemas relatados pelas lideranças indígenas.
\end{abstract}

Palavras-chave: luta, Mbya Guarani, saúde, ethos, cuidado.

\section{Introdução}

O objetivo deste artigo é discutir o sentido da luta indígena como dimensão necessária para a compreensão de saúde junto às comunidades, a partir da análise de enunciados presentes em comunicações públicas selecionadas, de lideranças Mbya Guarani ${ }^{1}$, em textos divulgados em jornais e expressões analisadas no documentário "Teko Rexaĩ: Saúde Guarani Mbyá" (Marin \& Calabi, 2012). Também se apresenta e discute reflexões emergidas em pesquisa de mestrado de uma das autoras deste artigo (Sousa, 2018), desenvolvida no campo da psicologia cultural, em sua vertente semióticoconstrutivista, articulada às preocupações presentes no serviço Rede de Atenção à Pessoa Indígena, do Instituto de Psicologia da Universidade de São Paulo (IPUSP). A pesquisa discutiu pontos de tensões emergidos no diálogo interétnico em torno das questões de saúde indígena, dando ênfase ao tema da saúde mental.

Salientamos que o termo saúde mental e as ações promotoras de saúde pressupõem a existência de ambientes onde sejam respeitados e protegidos os direitos civis, políticos, socioeconômicos e culturais de uma população ("OPAS/OMS apoia governos", 2016). Contudo, observamos a necessidade de cautela na utilização do termo quando tratamos de questões relativas à saúde indígena, na medida em que

\footnotetext{
*Endereço para correspondência: flavianarsousa@yahoo.com.br

1 Utilizamos a grafia Mbya Guarani, porém também é usual a terminologia Guarani Mbya e Guarani-Mbyá.
}

este foi concebido nas tradições das sociedades ocidentais e que, portanto, não foi fundamentado levando em conta, em toda sua profundidade e extensão, concepções produzidas a partir de epistemes que tomam como base as cosmologias indígenas. Os indígenas possuem suas próprias concepções de saúde e práticas xamânicas que, como veremos a seguir, a partir dos enunciados dos indígenas no material selecionado para análise, entram em tensão com as ações em saúde preconizadas e efetivadas nas políticas públicas do Sistema Único de Saúde (SUS). Longe de esgotar a compreensão das concepções indígenas em sua profundidade epistêmica, ontológica e ética, a presente pesquisa lidou com comunicações indígenas endereçadas a um público amplo, incluindo os agentes de saúde. Entendemos que essas comunicações visam a formação desses agentes e da militância que os apoia em seu processos de resistência e autoafirmação, a respeito de alguns princípios básicos que orientam as concepções e práticas de cuidado que visam efetivar nas parcerias. Desse modo, o aporte seletivo às produções antropológicas é subsidiário de uma reflexão aqui situada no campo da psicologia. Em nosso percurso de pesquisa, o aprofundamento da interdisciplinaridade com as produções etnográficas permitiu delinear noções psicológicas que potencializam a compreensão de nuances das expressões indígenas analisadas e oferecem subsídios para a continuidade das ações empreendidas no contexto da rede indígena, com possibilidades de generalização para outros contextos de atuação dos psicólogos, considerando a diversidade de povos e comunidades nas quais atuam psicólogos em políticas públicas. 


\section{Aproximações ao contexto da vida Mbya Guarani hoje e da noção de Teko Porã}

No ano de 2008, o povo Guarani somava cerca de 100.000 pessoas, as quais habitavam aldeias e comunidades no Brasil, Argentina e Paraguai (Grünberg \& Melià, 2008). Além desses países, há também comunidades Guarani que vivem na Bolívia, que em 2001 somavam 78.345 pessoas (Grünberg \& Melià, 2008).

Também no ano de 2008, a Fundação Nacional do Índio (Funai) estimou que no Brasil, os Mbya somavam 7.000 pessoas, distribuídas nos estados do Espírito Santo, Pará, Paraná, Rio de Janeiro, Rio Grande do Sul, Santa Catarina, São Paulo e Tocantins. No entanto, segundo colocação do Instituto Socioambiental, há controvérsias quanto a este número, pois esse povo tem como característica importante uma mobilidade intensa em sua dinâmica social, que envolve visitas aos parentes, que muitas vezes se estendem por longos períodos, estabelecendo assim intercâmbios de materiais para a produção de artesanatos e para a agricultura, rituais, entre outras atividades intercomunitárias que dificultam a obtenção de dados censitários mais precisos.

O povo Guarani tem sido comumente identificado na literatura por quatro subgrupos: os Mbya-Guarani; os Kaiowá (Pai-Taviterã); Guarani ou Nhandeva (Avá-Guarani) e os Ache-Guayaki, que guardam semelhanças no aspecto fundamental de sua cultura e organização sociopolítica. Porém, esses subgrupos mantém muitas diferenças, utilizadas como "marcadores étnicos" (Grünberg \& Melià, 2008, p. 3), tais como variações linguísticas, religiosas e no modo como se relacionam com o seu entorno.

Contudo, é possível notar, a partir da literatura antropológica, diferentes classificações nas categorias subgrupais do povo Guarani. Assim, por exemplo, Pissolato (2007) descreve quatro subgrupos Guarani: Kaiowa, Ñandeva, Mbya e Ava. Essas classificações não refletem, necessariamente, as formas de autoidentificação dos próprios indígenas, como indica Pierri (2013), pois as relações entre os Guarani caracterizam-se por serem intensas e fluidas. Pierri discute o sentido relacional do termo Mbya, apontando que ele é usado para designar relações entre familiares e parentes, desconsiderando a existência de fronteiras rígidas para o uso do termo no sentido da classificação de subgrupos. Então, as categorias "são sempre contextuais e, portanto, variáveis no tempo e no espaço" (Pierri, 2013, p. 24).

Aproximamo-nos da noção de Guarani de Teko Porã. Takuá (informação verbal) ${ }^{2}$ afirma que essa noção costuma ser rapidamente traduzida por "bem viver" e confundida com "viver bem", no sentido da acumulação capitalista e dos valores hegemônicos da sociedade brasileira. Contudo, Teko Porã expressa o sentido Mbya Guarani de boa e bela

2 Informação fornecida por C. Takuá em "Teko Porã, Teko Vai: desafios de praticar o bem viver em tempos sombrios", palestra apresentada na Ação Cultural Línguas Ameríndias, em São Paulo, em setembro de 2019. forma de existir no território, sendo o território uma condição necessária para esse modo de existir.

O modo de ser Guarani, o Nhande Reko compreende toda a dimensão do Teko Porã (bem viver), de modo que a promoção da saúde se efetiva em atividades do cotidiano, em conformidade com sua cultura. De acordo com Melià (2013), o bem viver é um "modo de ser, um bom estado de vida" (p. 194). O modo de ser Guarani e os aspectos de sua cultura não se manifestam apenas nos rituais da casa de reza, mas se faz presente na linguagem, na alimentação, nos cuidados com as crianças, na dança, na educação, enfim, em diversos aspectos da vida diária e coletiva. Buscam o bem viver no presente, através de relações que fazem sentido hoje e não somente como um anseio futuro, que está por vir.

Chamorro (1998) destacou aspectos relativos às concepções do bem viver indígena, nos quais as imagens de uma terra viva e da vida como processo contínuo de plenificação, bem como as práticas de reciprocidade, seriam os princípios norteadores dessa noção. O Teko Porã é um conceito que atravessa a experiência de vida do povo Guarani, pois a palavra teko significa "ser, estado de vida, condição, estar, costume, lei, hábito" (Melià, 2013), ou seja, é sua própria cultura. O modo de ser está diretamente ligado aos modos de produção da saúde. Na cosmologia Mbya Guarani, há vários aspectos que norteiam a dimensão da saúde, que não são institucionalizados, mas estão presentes na dinâmica da vida comunitária. A saúde faz-se presente no próprio conceito de Teko Porã, atravessando as atividades da vida desse povo e permanecendo por meio do modo de pensar e agir nas práticas cotidianas.

\section{Na fronteira entre concepções de saúde}

Entre concepções distintas de saúde emergentes em nosso campo de estudo, encontramos possibilidades de interlocução por meio de noções de saúde elaboradas no âmbito da fenomenologia hermenêutica de Gadamer (2006) e da reflexão ética sobre os discursos e práticas psicológicas proposta por Figueiredo $(2007,2008)$. A opção de entrar em diálogo com as concepções de saúde elaboradas por esses autores deve-se à sua pertinência com as elaborações teórico-metodológicas em desenvolvimento no âmbito do construtivismo-semiótico cultural, vertente da psicologia que fundamentou o percurso de pesquisa e que, desde 2008, dialoga com formulações da teoria antropológica do perspectivismo ameríndio, produzindo inovações conceituais ${ }^{3}$ no campo

3 A noção de multiplicação dialógica é uma dessas inovações, que emergiu como recurso conceitual para a reflexão sobre limites e pontos de interdição que participam do diálogo, explicitando processos de compartilhamento e não-compartilhamento de trajetórias entre diferentes perspectivas socioculturais (Guimarães, Lima Neto, Soares, Santos, \& Carvalho, 2019). Do ponto de vista metodológico, essas considerações levam à necessidade de se delinear como se dão as trajetórias de análise e interpretação dos enunciados, visando identificar as tensões relevantes para a análise interpretativa dialógica. 
da psicologia cultural (Valsiner, 2019). Cabe destacar que, nos primórdios das reflexões antropológicas que resultaram na proposição do perspectivismo ameríndio, a psicologia sócio-histórica e a hermenêutica tiveram um papel central ao influenciar algumas das estratégias e entendimentos do conhecimento produzido a partir das etnografias, de modo que os primeiros estudos da área foram considerados um tipo de etnopsicologia:

Tomar . . . a pessoa como objeto de estudo antropológico, embora pudesse cheirar a heresia, se justifica enquanto se pretende a procura de uma etnopsicologia, ou seja, a tentativa de aprender as categorias a que uma sociedade específica recorre para elaborar sua noção de pessoa. Para tanto, tivemos muito mais o que aprender com a chamada corrente de "psicologia histórica", do que com antropólogos que a ortodoxia entrava em territórios melhor demarcados. (Cunha, 1978, p. 1)

O construtivismo semiótico-cultural (CSC) em psicologia vincula-se à tradição da psicologia histórica, focalizando os processos básicos do existir humano, observando como a cultura está presente no sentir, no pensar e no agir em sociedade. A cultura é compreendida como um processo dinâmico, modificada, desconstruída e reconstruída a partir das relações eu-outro-mundo (Simão, 2010). Essa perspectiva teórico-metodológica visa um aprofundamento sobre as relações "afetivocognitivas sob as quais os fenômenos psicológicos se desenvolvem" (p. 54), no sentido de romper com as abordagens dicotômicas em psicologia que se restringiam em explorar a dimensão exclusivamente racionalista ou exclusivamente baseada nos afetos.

As noções de saúde e saúde mental, em desenvolvimento no âmbito do CSC, articulam-se com proposições de Gadamer (2006), para quem a saúde da mente não está dissociada da saúde do corpo, tampouco, de todos os processos culturais, biológicos, sociais e sanitários que ocasionam quadros de adoecimento de uma pessoa ou população. Gadamer (2006), ao refletir sobre o caráter oculto da saúde, discute a temática na era da ciência e da técnica, e realça, sobretudo, o caráter experiencial e psicossocial do processo saúde-doença, tomando a saúde como um estado de equilíbrio natural, do restabelecimento da ordem natural dos processos vitais. Assim, a doença estaria caracterizada enquanto perda de equilíbrio, afetando não somente a dimensão biológica, mas também a vida social da pessoa. O doente está suspenso, no entanto está ligado ao retorno à sua vida "como aquele ao qual falta alguma coisa" (p. 50). Ao tratar mais detidamente sobre a saúde mental, Gadamer (2006) entende essa dimensão enquanto equilíbrio, por representar justamente o estado da pessoa em sua totalidade, em sua relação com o mundo. A vida humana, quando ameaçada pela doença, mostra-se rompida em sua integralidade, de modo que uma doença sempre afetará o equilíbrio mental da pessoa (Gadamer, 2006).

A Organização Munidal da Saúde ("OPAS/ OMS apoiam governos”, 2016) pressupõe que a saúde mental depende da existência de ambientes respeitados e protegidos para a população. Destacamos que essa presunção não está sendo suficientemente considerada, como uma dimensão vital, no diálogo com sentidos peculiares presentes nas concepções do povo Mbya Guarani. Por conseguinte, consideramos importantes para as reflexões aqui propostas aquelas desenvolvidas por Figueiredo (2008), que apontam uma relevante articulação entre ética, morada e saúde:

Se pensarmos que a saúde, para além de qualquer critério médico e psicológico, pode ser vista como usufruto do corpo (e da mente), não será difícil reconhecer que somente quando se tem um espaço privilegiado de moradia é possível despertar no corpo e na mente toda sua capacidade de fruir, trabalhar e pensar. (p. 70)

A saúde, segundo Figueiredo (2008), está ligada ao modo de vida, à possibilidade de se constituir uma forma de habitar serena e confiada, que é a condição do gozar e experimentar o corpo de forma prazerosa e longe "dos riscos e das incertezas da sobrevivência" (p. 70). A noção de etnia tem sua origem no termo grego ethnos, utilizado para se referir às qualidades de um povo - pessoas que compartilham um ethos, ou seja, costumes, hábitos, princípios, valores, normas de ação e ideais. Figueiredo (2008) discute que a noção de ethos refere-se a uma forma de "propiciar, configurar, formar e constituir tanto os homens como seus mundos - suas moradas, tanto os sujeitos como seus objetos, tanto as experiências sociais quanto as experiências privadas e 'subjetivas' de cada indivíduo" (p. 48). $\mathrm{O}$ ethos, portanto, diz respeito às "instalações do humano" (p. 48), às formas de se habitar o mundo. Na medida em que o ethos de cada cultura pressupõe diferentes costumes e hábitos, por meio dos quais as pessoas podem construir suas moradas serenas e confiadas, os modos de coexistir e se relacionar com a cultura do outro são constitutivos das condições para que cada pessoa possa fruir, trabalhar, pensar, brincar e experimentar seus mundos - dimensões relevantes para a saúde humana (Figueiredo, 2008).

Então, cabe-nos refletir, especialmente no caso das populações indígenas, de que forma é possível habitar o mundo serena e confiadamente, usufruindo plenamente de seus corpos, sendo que suas moradas estão prejudicadas e são constantemente ameaçadas nos conflitos, dentre os quais, aqueles que envolvem a luta pela terra. Que saúde é possível promover numa situação em que os indígenas e suas comunidades percebem que está sendo violada sua condição de habitar serena e confiadamente as terras onde vivem em conformidade com seu ethos? 
As reflexões aqui propostas dialogam com experiências no âmbito da cultura e extensão dos últimos oito anos, em que construímos no Instituto de Psicologia da USP (IPUSP) a Rede de Atenção à Pessoa Indígena (Bertholdo \& Guimarães, 2018). A Rede Indígena teve como objetivo inicial compreender as vulnerabilidades psicossociais enfrentadas por comunidades indígenas de São Paulo; os direitos conquistados pelos povos indígenas nas últimas décadas; os caminhos para efetivação desses direitos trilhados pelas lideranças comunitárias; suas relações com a diversidade de cuidadores acionada pelas comunidades, envolvendo voluntários não indígenas, organizações não-governamentais e organizações governamentais; as articulações realizadas pelos movimentos indígenas e pelos modos de organização social das comunidades com a quais passamos a construir vínculos. Em 2015, a Rede Indígena tornou-se um serviço do IPUSP, sediada no Departamento de Psicologia Experimental, contando com a participação de preceptores indígenas, docentes, pós-doutorandos, pós-graduandos e graduandos em sua equipe.

No desenvolvimento de nossas atividades, permanecemos atentos aos processos de construção de sentidos e significados das experiências, observando a diversidade de compreensões a respeito das vulnerabilidades psicossociais enfrentadas pelas comunidades indígenas e das estratégias desenvolvidas por essas comunidades para existirem e resistirem em situações muito adversas. Dentre os temas emergidos nos diálogos, ganharam centralidade as lutas pela demarcação de terras, pela educação diferenciada de qualidade nas comunidades e por atendimentos à saúde de forma respeitosa e integrada às concepções de saúde próprias das tradições indígenas. Do ponto de vista da legislação brasileira, sabemos que a Constituição Federal de 1988 é muito clara ao assegurar aos indígenas o direito à organização social, baseada em seus costumes, linguagens, crenças e tradições, bem como à terra que tradicionalmente ocupam. É um dever do Estado proteger as expressões indígenas por meio de processos de educação e saúde diferenciados, que respeitem essas expressões.

\section{O dialogismo teórico-metodológico no contexto dos enunciados interculturais}

No âmbito do CSC, a cultura é compreendida como parte inerente das funções psicológicas humanas, intrínseca ao sistema psicológico da pessoa, e não como algo externo a ela, como no caso de organizadores causais externos. Toma-se como relevante para a psicologia, sobretudo, compreender a natureza dinâmica e processual do funcionamento da cultura nos sistemas psicológicos humanos, tanto intrapessoais quanto interpessoais. Nessa perspectiva, consideramos que as interações discursivas e comunicativas são elementos essenciais às práticas de saúde.
Refletimos sobre as interações discursivas e comunicativas a partir da dimensão de enunciado. Bakhtin (1997) propõe o enunciado como a unidade da comunicação discursiva e elemento de expressão da materialidade linguística; reflete que cada vez que é pronunciado, ganha um novo sentido, de forma que a compreensão não deve se restringir somente à palavra, sendo puramente textual, mas deve incluir, sobretudo, os fatores extralinguísticos ou extraverbais como entonações, sons, momento sócio-histórico, intenção de quem fala, enfim, o contexto da fala (Bakhtin, 1997). Com essa proposta, a relação viva entre as pessoas passa a ser o cerne da constituição do discurso. São três principais fatores que compõem o sentido de situação extraverbal, discutido por Bakhtin \& Voloshinov (1926): 1) "horizonte espacial comum dos interlocutores"; 2) "o conhecimento e a compreensão comuns da situação por parte dos interlocutores" e 3) "sua avaliação comum dessa situação" (p. 7). A situação extraverbal é parte constituinte do enunciado e não externa a ele, sendo o enunciado a unidade real da comunicação discursiva.

A teoria da linguagem de Bakhtin

... nos permite olhar, de forma analítica, as interações discursivas nos diversos campos da atividade humana e da comunicação. É nesse sentido que entendemos a importância do pensamento de Bakhtin para o campo da saúde, uma vez que a comunicação está presente nos diferentes processos ou eventos que aí se desenvolvem. De maior relevância, para nós, é a compreensão de que as necessidades de, e as intervenções em saúde são condições e ações humanas permeadas e construídas, com frequência, por atos comunicativos. (Corrêa \& Ribeiro, 2012, p. 332)

Em nosso esforço compreensivo das expressões indígenas selecionadas na pesquisa, percebemos a necessidade de se refletir sobre a emergência de tensões e trajetórias de sentido percebidas pelos indígenas como não compartilhadas nas práticas de saúde efetivadas nas políticas públicas. Nos contextos interculturais ou interétnicos, a relação dialógica não parte de um solo comum, levando-nos à suposição de que há uma precariedade na apreensão extraverbal compartilhada da situação em que os enunciados são expressos. Haveria, então, a necessidade de que um solo extraverbal comum, mesmo que temporário, passasse a ser construído em coautoria.

\section{Sobre as expressões Guarani tomadas em consideração no escopo da pesquisa}

Selecionamos do material de pesquisa analisado (Sousa, 2018) expressões Guarani contidas nos excertos da notícia "Índios fecham Rodovia dos Bandeirantes para exigir arquivamento de PEC e novas demarcações em 
São Paulo", da Rede Brasil Atual, compartilhada pelo coletivo Guarani Yvyrupa, em sua página do Facebook, e uma fala do Xeramõi ${ }^{4}$ João da Silva contida no documentário "Teko Rexaĩ: Saúde Guarani Mbyá"”.

A opção por selecionar esses materiais, metodológica e eticamente, diz respeito à possibilidade de entrar em contato com conteúdos que são produzidos, editados, reproduzidos ou publicados pela própria comunidade. Adicionalmente, esses enunciados são endereçados a um público que excede as próprias comunidades, explicitando sua preocupação com o que é noticiado e com o que é dito ao grande público. Assim, são esses conteúdos que representam seu movimento de luta e resistência.

Em nossas análises, os discursos Mbya Guarani direcionam-se, em parte, às normativas em saúde voltadas às populações indígenas, em especial às leis que implementam e consolidam o Subsistema de Atenção à Saúde dos Povos Indígenas (Sasi) criado em 1999: a) a Lei Arouca (Lei $n^{\circ}$ 9.836, de 23 de setembro de 1999); b) a Política Nacional de Atenção à Saúde Indígena (Portaria $\mathrm{n}^{\mathrm{o}} 254$, de 31 de janeiro de 2002); c) a Política de Atenção Integral à Saúde Mental das Populações Indígenas (Portaria $\mathrm{n}^{\mathrm{o}} 2.759$ de 25 de janeiro de 2007).

Como aqui consideramos que os enunciados engendram uma alteridade que está sendo contestada, a quem se está dirigindo uma voz, consideramos como contraponto desses materiais os discursos do não indígena, expressos pela legislação de saúde, que vemos refletidos nas falas indígenas. Entendemos que os discursos indígenas refratam-se a partir do encontro com os discursos não indígenas dispostos nos materiais analisados e vice-versa, gerando uma atmosfera social particular (Bakhtin, 1989). A atmosfera social seria dada por essa refração, isto é, pela mudança de direção que a palavra está fazendo em seu encontro com o que é estrangeiro. Mas dado o caráter dialógico, essa refração não é um simples rebote da palavra entre a palavra de outrem para outra palavra estrangeira, mas de cada encontro, em cada resposta que encontra a palavra ela está mudando, "encontrando seus próprios contornos

4 Xeramõi $\mathrm{e}$ Xejary'i são termos Guarani utilizados para se referir a pessoas que possuem grande sabedoria, em geral as mais velhas da comunidade e aquelas que são consideradas lideranças espirituais, pajés ou xamãs.

5 Os materiais tomados para análise foram 82 notícias produzidas e/ou veiculadas por dois coletivos indígenas Mbya Guarani - a Comissão Guarani Yvyrupa e o coletivo Tenonderã Ayvu - e por quatro entidades indigenistas - Conselho Indigenista Missionário; a Comissão Pró Índio; o Centro de Trabalho Indigenista e o Instituto Socioambiental. Foram selecionadas notícias que continham maior relação com o tema da saúde mental indígena abarcando o período de agosto de 2010 a junho de 2016. A opção de recorte desse período aconteceu por priorizarmos publicações que fossem mais atuais e posteriores à criação da Secretaria Especial de Saúde Indígena (Sesai), no ano de 2010. O documentário "Teko Rexaĩ: Saúde Guarani Mbyá" também compôs os materiais de pesquisa por apresentar discursos sobre saúde proferidos por lideranças indígenas de diferentes aldeias do estado de São Paulo. Trata-se de um trabalho produzido no contexto do Projeto Ka'aguy Poty - Flores da Mata em parceria com falas dos Mbya Guarani, que expressam suas preocupações com a transmissão intergeracional dos saberes sobre saúde. semânticos" (Bakhtin, 1989, p. 94). Então, para entender os enunciados dos povos indígenas é preciso ter em vista aquilo que se contesta e a quem se endereçam suas falas, como o SUS, os apoiadores e as lideranças comunitárias. Nesse sentido, segundo Bakhtin (1989), os enunciados "estão cheios de enunciados ... cheios de palavras alheias de diferentes graus de alteridade ou de assimilação, de diferentes graus de conscientização e de manifestação" (p. 279). Portanto, não podemos considerar a fala indígena isolada daquelas que servem como contraponto delas.

\section{A compreensão dos enunciados dos Guarani desde o dialogismo em psicologia cultural}

Em termos analíticos, é relevante considerar o caráter dialógico da palavra no sentido de palavra viva, segundo Bakhtin (1989). A palavra, segundo este autor, é impregnada de múltiplos pontos de vista e está sempre orientada para a palavra de um outro. Portanto, a análise e discussão sobre o que, para quem e quando os próprios Guarani dizem é de suma importância para compreendermos o que estão colocando como pauta para a garantia de saúde e para poder viver o Teko Porã. A palavra proferida, para o Guarani, relaciona-se à permanência da vida e atua como fonte de conhecimento e sabedoria. Pissolato (2007) aponta que a noção de Nhe'e (alma, palavra) seria "enviada pelos deuses como princípio de consciência e autonomia pessoal" (p. 416). Melià (2010) também ressalta a relevância da palavra para os Guarani ao colocar que "a história de um guarani é a história de suas palavras", sejam elas ditas, escutadas, sussurradas na vida íntima ou pronunciadas numa assembleia, marcando a centralidade dessa dimensão na consciência de si, de estar no mundo e de resistir.

Selecionamos trechos da fala da liderança Marcos Tupã, coordenador da Comissão Guarani Yvyrupa, que integram a notícia "Índios fecham Rodovia dos Bandeirantes para exigir arquivamento de PEC e novas demarcações em São Paulo".

A notícia versa sobre três razões políticas que motivaram o fechamento da rodovia: 1) o posicionamento contrário à PEC $215^{6}$; 2) a exigência que o então ministro da Justiça José Eduardo Cardozo publicasse imediatamente as portarias declaratórias de duas terras indígenas (TI) localizadas na capital paulista, a TI Tenondé Porã e a TI Jaraguá; 3) o fim dos processos judiciais movidos pelo governo do estado de São Paulo contra povos Guarani, cujos territórios se sobrepunham aos limites dos parques estaduais. Além das três razões políticas, os Guarani buscaram dar visibilidade à questão histórica do culto à imagem dos bandeirantes, conhecidos pelos povos tradicionais como assassinos de índios. Essa manifestação

\footnotetext{
6 Proposta que propõe alterar a Constituição Federal para transferir ao Congresso Nacional a decisão final sobre a demarcação de terras indígenas, territórios quilombolas e unidades de conservação no Brasil.
} 
fez parte da jornada nacional de lutas convocada pela Articulação dos Povos Indígenas do Brasil (APIB) para interromper o avanço da PEC 215 no Congresso Nacional.

Se não tem $\mathrm{PEC}$, dialogamos com o governo. Com a ameaça da PEC, não tem outro jeito: temos de lutar. . . . A PEC 215 acaba com qualquer garantia de demarcação de novas terras indígenas no país. . . Por isso, estamos mobilizados nacionalmente. Queremos que a proposta seja arquivada: sua aprovação levará a mais confrontos e mais genocídio, porque os povos indígenas não ficarão de braços cruzados. . . . Em São Paulo, vivemos em áreas muito pequenas. As famílias cresceram bastante e o espaço não permite que vivamos à nossa maneira. O que temos são apenas fragmentos de terra. Não dá para desenvolver nossos saberes e práticas, nem transmiti-los às crianças. A correção dos limites permitirá que tenhamos mais mata e espaço para nossas roças e atividades tradicionais. . . Como indígenas, não pensamos em desmatar. Temos uma forma de viver, tradicionalmente, junto à natureza. . . . Acreditamos que estar perto do mar, dentro da Mata Atlântica, nos dá fortaleza espiritual para buscar a "terra sem mal" que estabelecem nossas crenças. A maioria dessas áreas, hoje, está dentro de parques estaduais. E somos acusados de invasores de parques... Queremos que o governo retire essas ações judiciais, reconhecendo a permanência dos indígenas nas terras que estão em sobreposição, e que possa haver uma gestão compartilhada entre governo do estado, povos indígenas e Funai. Não é coincidência que a menor terra indígena do Brasil é atravessada por uma estrada com esse nome [Rodovia dos Bandeirantes]. Só querem defender o grande poder econômico: os interesses de grandes sojicultores, pecuaristas e madeireiros, que financiam esses parlamentares. Deixam de lado a preservação, os indígenas, todo o resto. (Breda, 2013)

Esse discurso de Marcos Tupã aponta para uma série de reflexões sobre o enfrentamento e as dificuldades cotidianas das comunidades Mbya Guarani. Selecionamos alguns pontos nos quais é possível observar as tensões com as quais as comunidades lidam atualmente.

Marcos Tupã ressalta a importância da demarcação dos territórios para que sejam respeitados, já que são espaços necessários para a sobrevivência da cultura indígena. Com o crescimento das famílias nas comunidades do Jaraguá, o espaço tornou-se pequeno para a viabilidade da transmissão dos conhecimentos entre gerações. Com a correção dos limites da demarcação da TI, segundo a reivindicação dos Guarani, as comunidades poderão ter maior acesso à mata, permitindo o cultivo das roças, dentre outras atividades tradicionais.
Outra tensão importante relaciona-se à localização geográfica das aldeias. Morar próximo à serra do mar tem sentido cosmológico, como expressa a liderança: "Acreditamos que estar perto do mar, dentro da Mata Atlântica, nos dá fortaleza espiritual para buscar a "terra sem mal' que estabelecem nossas crenças" (Breda, 2013). Fica evidente que a luta pelos territórios é, muitas vezes, por lugares que já eram tradicionalmente ocupados pelos Guarani e que também guardam um sentido dentro de sua cosmologia. A luta não é apenas por um pedaço de terra, mas sim por um território onde possam viver plenamente sua cultura, tendo em vista que a compreensão do território Guarani ultrapassa sua fragmentação, imposta nos processos de demarcação.

A demarcação da terra, em termos de promoção de saúde, é considerada pelos Guarani como condição primeira para que possam dar encaminhamentos na direção de possíveis resoluções para os demais problemas sociais que agravam as condições de saúde das comunidades. Esses problemas vão desde os riscos provenientes da vulnerabilidade social, como o uso de álcool e outras drogas; exposição a situações de violência, que geram dificuldades no convívio comunitário; entristecimento e suicídio, e até mesmo o contágio por epidemias e demais doenças ocasionadas pela falta de saneamento básico e pela privação de alimentação adequada (Conselho Indígena Missionário, 2016).

A busca pela regularização formal das terras ocupadas visa a garantia da permanência do povo Mbya Guarani em seu território. As lutas pelas demarcações vieram se intensificando nos últimos anos, principalmente após a década de 1990. Tendo em vista a precariedade das condições atuais que muitas comunidades ainda enfrentam, em virtude dos interesses imobiliários e da sistemática negação ao direito da terra, emerge a compreensão de que esse enfrentamento é necessário (Ladeira, 2007).

O tekoa, manifestação do teko, um modo de ser, não se define inicialmente e nem somente pela dimensão objetivo-instrumental do território espacializado, mas compreende o simbolismo e suas conotações subjetivofuncionais ${ }^{7}$. O tekoa, lugar onde se dá o modo de ser $\mathrm{e}$ de viver Mbya Guarani é situado numa terra imbuída de valores e investimentos simbólicos (Pissolato, 2007). Assim, o tekoa é um lugar ao qual se pertence, do qual se faz parte, para além de algo que pertence a alguém enquanto propriedade.

Parte da reivindicação dos indígenas, ao fecharem a Rodovia dos Bandeirantes em 2013 - ano em que houve uma intensa mobilização dos coletivos Mbya Guarani na luta por seus direitos -, diz respeito à retirada dos processos judiciais movidos pelo governo do estado de São Paulo contra as comunidades que se encontram em territórios que se sobrepõem aos

\footnotetext{
7 Para a compreensão da relação entre as dimensões objetivo-instrumental e subjetivo-funcional da ação simbólica em psicologia cultural, consultar Boesch (1991).
} 
limites de parques estaduais. Marcos Tupã comenta que o Estado alega que os indígenas irão desmatar estas áreas e, com essa alegação, move ações judiciais para as desocupações. Já os Guarani justificam sua permanência tendo em vista que o modo de viver tradicionalmente no território é "junto à natureza" (Breda, 2013). Compreendemos, portanto, que para os indígenas a cultura se dá na natureza e não fora dela, o que os leva à proposição de um modo de gestão compartilhada com as representações institucionais. Mais uma vez, os pontos de vista contrapõem-se: como os processos judiciais se efetivam segundo normas elaboradas pelo Estado, os Guarani persistem na luta contra esses processos, expressando suas motivações para permanecerem em seus territórios.

O segundo discurso selecionado para a presente reflexão é um excerto de fala do Xeramõi João da Silva, da aldeia de Itaóca - no município de Mongaguá, São Paulo -, contida no documentário "Teko Rexaĩ: Saúde Guarani Mbyá", em que ele contrasta sua concepção de saúde com a postura do Estado em relação aos conhecimentos de saúde tradicional indígena:

Hoje, a Funasa é responsável por todas as questões relacionadas à nossa saúde. Por isso, quando falamos que sabemos sobre remédios, eles querem saber se a gente pode de verdade curar as doenças. Eles só vão acreditar se virem que a gente curou mesmo. Se não for assim, eles falam: "é mentira dos índios, eles não sabem". Eles falam assim. Isso me incomoda. Por isso, acho que devemos mostrar. Acho que devemos mostrar umas coisas boas para eles, mas o que é mais sagrado, o que é só para nós, a gente esconde. E uma das coisas que a gente tem que esconder é a sabedoria dos nossos Xeramõi, pois nem todas as pessoas da aldeia têm esse conhecimento. "Como você faz?", "como você cura?", "como é isso?". Não temos permissão para falar assim com eles. Não podemos perguntar, pois não faz parte do mundo material e sim do mundo espiritual. A sabedoria vem de Nhanderu ${ }^{8}$. É por isso que os Xeramõi têm força e poder de cura. Acho que isso deve ficar em segredo, meus parentes. Tem três coisas que são importantes para a nossa saúde: os remédios da mata, as curas feitas pelos líderes espirituais e os batizados das crianças. São três coisas realmente da nossa cultura. Hoje em dia, quando nossos filhos ficam doentes, levamos direto para os médicos. Mas se vocês estiverem realmente preocupados, mesmo eles estando no médico, vocês devem colocar o Ka'a (erva-mate) na casa de reza e pedir para o nosso líder espiritual rezar por eles. Aí ele vai

8 A palavra Nhanderu pode ser literalmente traduzida como "nosso pai" e é muitas vezes utilizada para se referir aos primeiros ancestrais criadores do mundo Guarani. poder se conectar espiritualmente com as crianças para ajudar a curá-las. (Marin \& Calabi, 2012)

Podemos analisar nessa fala a preocupação dos mais velhos com a transmissão dos conhecimentos tradicionais de cura e dos conhecimentos das plantas, dentre os muitos aspectos que envolvem a dimensão da saúde. Observamos que o Xeramõi se incomoda com representantes das instituições do Estado que colocam em dúvida os saberes indígenas ao questionarem se suas práticas são realmente eficazes.

No excerto acima, é presente uma tensão comum nos demais enunciados presentes ao longo do documentário: revelar ou não os conhecimentos relacionados aos cuidados e tratamento de saúde Mbya Guarani. Mostra-se um pouco, mas não se mostra tudo, nem o que é mais importante, pois esses conhecimentos devem ser mantidos em segredo, compartilhados apenas entre alguns membros da comunidade. $\mathrm{O}$ enunciado demonstra uma preocupação com forma de manter a tradição que, mesmo quando questionada e colocada em dúvida sobre sua eficácia, expressa uma forma de resistência, concebendo que certos saberes devem ser resguardados para certas pessoas. Em nossas análises do documentário, observamos que é muito presente entre os anciãos a preocupação com a postura ética daquele que acessa os conhecimentos tradicionais, de modo que a pessoa precisa estar preparada para fazer uso responsável desses conhecimentos.

O Estado, por sua vez, é oficialmente responsável por ofertar certo cuidado em saúde, por meio da atenção diferenciada, mas, segundo o Xeramõi, os agentes do Estado julgam o saber da comunidade, exigindo sua comprovação. Caso contrário, os indígenas correm o risco de serem chamados de mentirosos. Percebemos um distanciamento entre a posição Mbya Guarani e a posição do Estado em relação às questões de saúde, evidente na expressão de dúvida e desconfiança sentida pelo Xeramõi. A exigência de comprovação pressupõe que o interlocutor não sabe ou não conhece, ou que seu conhecimento é menos legítimo quando contraposto aos referenciais epistêmicos e científicos que sustentam a forma de intervenção fomentada pelo Estado. Nesse cenário, as políticas públicas que ofertam a assistência em saúde são executadas sem considerar suficientemente a própria perspectiva de saúde dos indígenas. Por outro lado, a portaria que estabelece as diretrizes gerais para a atenção integral em saúde mental dos povos indígenas ressalta que, para identificar os problemas, criar alternativas e mobilizar recursos para a construção de soluções para os problemas vivenciados pelas comunidades, é preciso "apoiar e respeitar a capacidade das diversas etnias e das comunidades indígenas, com seus valores, economias, tecnologias, modos de organização, de expressão e de produção de conhecimento" (Brasil, 2007). 
Ainda segundo o que foi expresso por João da Silva, os Xeramõi não possuem apenas uma sabedoria material, mas sim espiritual, que vem de Nhanderu e que, por isso, deve ser mantida em segredo. Podemos fazer um contraponto entre o discurso legitimado por uma compreensão científica de mundo e o discurso do xamã. Para o primeiro tipo de discurso, trazido pelos agentes vinculados às políticas públicas de saúde, o conhecimento deve ser validado pelas metodologias científicas, com bases fortemente argumentativas e fundamentadas nos princípios do racionalismo ocidental. Já os procedimentos sistemáticos de cura do xamã são fundamentados no que afirmam ser uma sabedoria espiritual vinda de Nhanderu, inerente ao sistema de compreensão dos indígenas, que, por sua vez, se valem de suas concepções cosmológicas expressas em narrativas míticas que conferem sentido a seus ritos, como os rituais de batismo e a cura da erva $K a^{\prime} a$ (erva-mate).

Em dado momento, o Xeramõi afirma que quando os "filhos ficam doentes, levamos direto para os médicos, mas também devemos colocar o Ka'a" (Teko Rexaĩ: Saúde Guarani Mbyá, 2012). Nessa direção, é interessante ver como a perspectiva indígena é agregadora, pois ao mesmo tempo que atribui valor aos seus conhecimentos tradicionais, não exclui o outro sistema de conhecimento. Há uma valorização dos conhecimentos tradicionais de cura, mas também há o reconhecimento do importante papel da medicina ocidental. Os dois saberes podem ser agregados, na medida em que os saberes tradicionais não sejam abandonados pela comunidade. Ainda na fala do Xeramõi, são elencados os três aspectos fundamentais para a saúde, próprios da cultura Mbya Guarani: os remédios da mata; as curas feitas pelos líderes espirituais e os batizados das crianças.

Embora dito de forma bastante sintética, cada item elencado pelo Xeramõi encerra processos socioculturais e ambientais muito complexos, para os quais, então, os profissionais de saúde são convocados a colaborar. Assim, para que haja os remédios da mata é necessário que haja um território com floresta nativa preservada, que as pessoas transitem na mata reconhecendo e respeitando os remédios que ali estão, o que, na concepção Guarani, nos leva a uma necessária compreensão dos seres donos de certos domínios da mata e das formas de caminhar com atenção e cuidado em relação a estes (Pissolato, 2007). Ouvir sobre as curas feitas pelos líderes espirituais nos coloca em contato com seus processos de formação, que não passam por uma educação formal escolarizada, mas por uma série de experiências pessoais e práticas rituais, como cantos, danças, restrições alimentares etc.

Finalmente, os batizados das crianças mencionados pelo Xeramõi João da Silva, apontam para uma concepção Mbya Guarani sobre a relação entre o nome da criança e sua saúde (Pissolato, 2007): é preciso reconhecer o lugar da pessoa no mundo por meio de seu nome, para que ela possa pôr em prática a boa e bela forma de existir no território. Adoecer, portanto, parece fazer parte de um processo de não conformação da pessoa a um lugar ou conjunto de experiências - nessa situação, a morte pode ser um destino inevitável, entendida como parte de uma travessia.

\section{Possíveis interlocuções da psicologia com os discursos indígenas}

O sentido de um enunciado aponta para outras vozes que se conectam a uma dada expressão. Essas vozes, por sua vez, são articuladas por aqueles que interagem com a expressão, estabelecendo novas conexões não observáveis imediatamente nas palavras expressas. Portanto, em vez de nos atermos somente aos conteúdos explícitos, ou buscarmos uma verdade essencial de fundo em relação àquilo que é dito, o encaminhamento da compreensão dialógica aponta para a produção de novos enunciados a partir do que foi expresso previamente, a emergência de uma novidade como resposta à cadeia de enunciação.

Em nosso contexto de construção do sentido da experiência no diálogo, entre as diferentes matrizes culturais presentes, existem tensões e uma relação hierarquicamente assimétrica. A assimetria manifesta-se na medida em que uma perspectiva (do Estado) sobrepõe-se a outra (indígena) nos desenvolvimentos das práticas de saúde institucionalizadas. Observamos a partir dos enunciados das lideranças Mbya Guarani que existem muitas tensões entre os discursos e práticas promovidas pelo Estado e pelas políticas públicas e os discursos e práticas propostas pelos próprios Guarani. Nesse contexto, há uma relação de poder em que um saber tenta se sobrepor ao outro ${ }^{9}$. Contudo, se por um lado os discursos e práticas Guarani agregam o saber da medicina ocidental, por outro lado eles não se sentem escutados com a devida profundidade em suas perspectivas de saúde.

Uma das tensões diz respeito à própria classificação identitária do povo Mbya Guarani, promovida pelo Estado, que os considera um subgrupo étnico com traços culturais fixos. Ao contrário, podemos analisar que seus processos de autorreconhecimento étnico diferem das formas descritas pela psicologia social clássica (Tajfel, 1984; Turner, Oakes, Haslam, \& McGarty, 1994) uma vez que não respondem a critérios perceptuais fixos, mas a processos de vivências dinâmicas e fluidas, baseados nas experiências cotidianas. Podemos observar que estamos diante de povos que dificilmente podem ser

9 Uma profunda reflexão sobre os processos de legitimação dos discursos e práticas no campo da saúde foi empreendida por Foucault (1963/2017) em sua genealogia do nascimento da clínica médica. Contudo, tal aprofundamento foge ao escopo do presente artigo, em que optamos por focalizar a compreensão de enunciados de lideranças Mbya Guarani, estabelecendo possíveis e iniciais articulações com concepções no campo da psicologia em sua vertente construtivista semiótico-cultural. 
classificados em categorias identitárias que dão conta de grupos claramente diferenciáveis entre si.

$\mathrm{O}$ conceito de ethos, relacionado à forma de habitar o mundo (Figueiredo, 2007, 2008), permite nos aproximarmos dos modos de conceber a saúde Mbya Guarani. Se os povos indígenas têm, ou melhor, já possuíam uma forma de habitar seus territórios, é fundamental escutá-los para a compreensão, o reconhecimento e a interpelação do que os indígenas nomeiam e apontam como promotores de adoecimento, as experiências que ocasionam a perda do equilíbrio natural de sua morada (Gadamer, 2006).

Para Figueiredo (2008), é essencial sentir-se em casa, seja habitando as moradas simbólicas ou as moradas físicas (estruturais), possibilitando a criação de "experiências de encontro da alteridade e consequentes acontecimentos desalojadores" (p. 73). É no encontro com o outro que a ética perpassa a "troca regulada de afetos e obrigações recíprocas entre indivíduos" (p. 73), estabelecendo as relações de confiança em maior ou em menor grau. Essas relações permitem que as pessoas possam ultrapassar serena e confiadamente os acontecimentos desalojadores, como aqueles que criam rupturas que podem ser intensas e dificultar as condições de se estar no mundo.

Portanto, enquanto a psicologia não compreender que a morada dos povos indígenas está concretamente em colapso, não conseguirá ofertar um cuidado eficaz para essas populações. As ações em psicologia precisam se atentar para essa dimensão, com vistas ao fortalecimento das comunidades, apoiando-as para que consigam manter suas moradas em condições propícias ao bem viver. Considerando o contexto atual, em que a morada Guarani encontra-se em colapso, a saída que esses povos têm encontrado para combater essa realidade é lutar pelo resgate de seu próprio ethos - nesse movimento eles encontram a saúde. A luta, portanto, nas condições atuais, não é uma escolha, mas sim, uma forma de manter ou criar condições favoráveis para promoção da saúde, e, sobretudo, para sua permanência.

É relevante que os agentes de cuidado estejam atentos ao sentido das expressões indígenas, estendendo essa compreensão àquilo que se afirma para além das palavras, que escapa ao conteúdo verbal presente nas práticas rituais, nos cantos, nas danças, no convívio comunitário e nas mobilizações de luta por seus direitos.

Uma forma possível para o compartilhamento da experiência depende de um processo de sintonização (Guimarães, 2016), para que se possa construir um solo comum no qual relações mais horizontais, equitativas, possam se efetivar. Cada cultura organiza seus ritmos por meio de seus ritos, que consistem nas tarefas básicas do cotidiano, e para estar em sintonia seria preciso dividir na experiência do tempo um ritmo comum. O compartilhamento dos ritmos, portanto, é o que estaria na base de construção de planos comuns entre distintas posições (Guimarães, 2013; Guimarães et al., 2019; Jensen \& Guimarães, 2018). A indisponibilidade de abertura para a alteridade, por sua vez, gera rupturas e uma impossibilidade de sintonização dos ritmos e dos afetos e, consequentemente, produz estereótipos, reforçando o preconceito. A postura relatada dos agentes do Estado, ao duvidar dos conhecimentos de saúde indígena, parece ser constitutiva de uma "barreira semiótica" (Guimarães, 2016), que não permite a emergência de uma sintonização afetiva, tampouco a comunicação dialógica entre as duas culturas.

\section{Considerações finais}

Embora esta pesquisa seja fruto de atividades acadêmicas de pesquisa, cultura e extensão localizadas, consideramos que seus resultados apresentam contribuições significativas para a compreensão do papel do psicólogo em sua relação com as comunidades, na medida em que a atuação de profissionais da área tem sido cada vez mais frequente junto às populações indígenas: na atenção básica à saúde, promovida em equipamentos vinculados aos distritos sanitários especiais indígenas; na compreensão das especificidades culturais dessa população em contextos educacionais; na compreensão de vulnerabilidades psicossociais decorrentes do processo socio-histórico latino-americano colonial e pós-colonial, bem como na formulação de políticas públicas para a promoção articulação social em contextos interculturais.

A formação e atuação do psicólogo nos serviços de saúde, por sua vez, vincula-se à noção de saúde compreendida pela Organização Pan-Americana da Saúde (OPAS), que integra a Organização Mundial da Saúde (OMS), segundo a qual o conceito de saúde ultrapassa o simples estado de ausência de doença, mas compreende o "bem estar físico, mental e social" ("OPAS/OMS apoia governos", 2016). A pesquisa aqui discutida, contudo, identificou tensões emergentes entre duas diferentes perspectivas sobre a saúde indígena. De um lado, as formulações presentes em documentos de instituições que se pautam em concepções ocidentais de saúde, tais como a OMS, o SUS e o Sistema Conselhos de Psicologia. De outro lado, estão os discursos de lideranças indígenas, com ênfase naqueles expressos por lideranças do povo Mbya Guarani, que por meio de seus modos de vida e cosmologia atribuem sentido próprio ao processo saúde-doença, que vai além do corpo físico, deslocando suas reflexões do plano biológico e social para os contextos cosmológicos sociais e morais (Langdon, 2005). Entendemos que essas perspectivas apresentam concepções e propõem práticas de cuidado em saúde distintas, que precisam ser observadas com cautela na atuação profissional.

Verificamos que, apesar das políticas públicas, com o advento do SUS, terem ampliado o modo de compreensão da saúde - não se restringindo somente ao aspecto físico 
e biológico, e incluindo as dimensões sociais, o ambiente e cultura - essa abertura não tem alcançado a percepção dos indígenas quanto ao respeito a suas cosmovisões. Por exemplo, mesmo que a OMS ("OPAS/OMS apoia governos", 2016) compreenda o ambiente enquanto lugar de trocas, propício para produção de sentidos de uma comunidade, a noção de território para os Mbya excede suas dimensões objetivo-instrumentais, agregando todo um simbolismo articulado pelas noções de Nhande Reko e Teko Porã. Por um lado, a OMS ("OPAS/OMS apoia governos", 2016) pressupõe que para assegurar a promoção de saúde mental é necessário que os ambientes sejam respeitados e protegidos, por outro lado os Guarani têm lutado justamente nessa direção, protegendo sua compreensão do ambiente e realizando práticas coerentes com essa compreensão, como condição primeira para que possam viver e fazer $a$ vida durar (Pissolato, 2007).

Ao refletirmos sobre as concepções de saúde e cuidado desde um enfoque do construtivismo semióticocultural (CSC) e suas interfaces com a ética, observamos a necessidade de realizar uma crítica às assimetrias que levam ao silenciamento ou imposição de um modo de vida sobre outro. A compreensão dos caminhos de luta e resistência na promoção da saúde Mbya Guarani depende da exposição dos agentes de cuidado aos aspectos extraverbais compreendidos nas práticas culturais e na vida comunitária, visando à construção de um solo comum para o diálogo como condição para uma oferta de cuidado mais eficiente, respeitosa e, sobretudo, responsável com os povos indígenas.

\section{Struggle and resistance: dimensions for health promotion Mbya Guarani}

Abstract: This paper discusses how the struggle of the Mbya Guarani people can be comprehended as a necessary dimension for the study of health care promotion. Struggle that happens in a situation manifested by the communities that includes the experience of a series of conflicts denounced as Brazilian State disrespect to their constitutional rights. We developed a dialogical analysis of discourses uttered by Mbya Guarani leaders, published by indigenous associations and in the documentary "Teko Rexaĩ: Saúde Guarani Mbyá". We discussed the tensions between the Guarani conception of Teko Porã and what is proposed by the Brazilian Subsystem of Indigenous Health Attention. We argue that the conceptions of health and care, from the framework of Semiotic-Cultural Constructivism in psychology and its interfaces with the ethical reflection, should consider the indigenous ethos. It allow us to rethink about the role other the healthcare agents in relation to the issues reported by the indigenous leaders.

Keywords: struggle, Mbya Guarani, health, ethos, care.

\section{Lutte et résistance: les dimensions de la promotion de la santé Mbya Guarani}

Résumé: Cet article met en question la manière dont la lutte du peuple Mbya Guarani peut être considerée comme une dimension nécessaire pour l'étude de la promotion de la santée. Elle se déroule dans un contexte où les communités expriment une série de conflits dénoncés comme le manque de respect de l'Etat Brésilien à leurs droits constitutionnels. On a réalisé une analyse dialogique des discours des leaders Mbya Guarani dans les nouvelles produites par les groupes indigènes et aussi, dans le documentaire "Teko Rexaï: Saúde Guarani-Mbya". Les tensions, entre la conception guaraní de Teko Porá et les dispositions du Sous-système d'Atencao à Saúde Indigène, sont discutées. Nous soutenons que les conceptins de la santé et des soins, au point de vue du constructivisme sémio-culturel dans la psycologie et ses interfaces avec la réflexion éthique, devraient tenir compte de l' ethos autochtone. Cela permet de repenser le rôle des agents de la santée en rélation avec les problèmes rapportés par les leaders autochtones.

Mots-clés: lutte, Mbya Guarani, santé, ethos, soins.

\section{Lucha y resistencia: dimensiones para la promoción de la salud Mbya Guarani}

Resumen: Este artículo discute cómo la lucha indígena del pueblo Mbya Guarani puede ser considerada como dimensión necesaria para el estudio de la promoción de salud. Lucha que se da en un contexto en que las comunidades manifiestan una serie de conflictos denunciados como falta de respeto desde el Estado brasilero a sus derechos constitucionales. Se realizó un análisis dialógico de discursos de líderes Mbya Guarani en noticias producidas por colectivos indígenas, y en el documental "Teko Rexaĩ: Saúde Guarani Mbyá". Se discute las tensiones entre la concepción Guarani de Teko Porã y lo previsto por el Subsistema 
de Atenção à Saúde Indígena. Argumentamos que las concepciones de salud y cuidado, desde el foco del constructivismo semiótico-cultural en psicología y sus interfaces con la reflexión ética, deben considerar un ethos indígena. Esto permite repensar el papel que tienen los agentes de salud en relación a los problemas relatados por los líderes indígenas.

Palabras clave: lucha, Mbya Guarani, salud, ethos, cuidado.

\section{Referências}

Bakhtin, M. (1989). Teoría y estética de la novela: Trabajos de investigación. Madrid: Taurus.

Bakhtin, M. \& Voloshinov, V. N. (1926). Discurso na vida e discurso na arte: Sobre poética sociológica (C. A. Faraco \& C. Tezza, trad.). New York: Academic Press.

Bertholdo, M. \& Guimarães, D. S. (2018). Amerindian support network. In S. Schliewe, N. Chaudhary, \& G. Marsico (Eds.)., Cultural psychology of intervention in the globalized world (pp. 119-134). Charlotte: Information Age Publishing.

Boesch, E. E. (1991). Symbolic action theory and cultural psychology. Berlin: Springer Verlag.

Brasil (2007, 25 de outubro). Portaria $n^{\circ} 2.759$. Estabelece diretrizes gerais para a Política de Atenção Integral à Saúde Mental das Populações Indígenas e cria o Comitê Gestor. Recuperado de https://bityli.com/RY1I4

Breda, T. (2013, 26 de setembro). Índios fecham rodovia por arquivamento de PEC e novas demarcações em São Paulo. Rede Brasil Atual. Recuperado de https://bit.ly/31J4MQC

Cunha, M. C. (1978). Os mortos e os outros: Uma análise do sistema funerário e da noção de pessoa entre os índios Krahó. São Paulo, SP: Hucitec.

Chamorro, G. (1998). O Rito de Nominação numa aldeia Mbyá-Guarani do Paraná. Diálogos, 2(1), 201-216. Recuperado de https://bit.ly/33UaVn6

Conselho Indigenista Missionário (2016). Relatório de violência contra os povos indígenas: dados de 2015. Recuperado de https://bityli.com/jTw6J

Corrêa, G. T., \& Ribeiro, V. M. B. (2012). Dialogando com Bakhtin: algumas contribuições para a compreensão das interações verbais no campo da saúde. Interface - Comunicação, Saúde, Educação, 16(41), 331-342. doi: 10.1590/S1414-32832012005000023

Figueiredo, L. C. M. (2007). A metapsicologia do cuidado. Psychê, 11(21), 13-30. Recuperado de https://bityli.com/O9Qoo

Figueiredo, L. C. M. (2008). Revisitando as psicologias: Da epistemologia à ética das práticas e discursos psicológicos (4a ed.). Petrópolis, RJ: Vozes.

Foucault, M. (2015). O nascimento da clínica (R. Machado, trad., 7a ed.). Rio de Janeiro, RJ: Forense universitária. (Trabalho original publicado em 1963)

Gadamer, H. G. (2006). O caráter oculto da saúde (A. L. Costa, trad.). Petrópolis, RJ: Vozes.

Grünberg, G., \& Melià, B. (2008). Guarani Retã: Os povos Guarani na fronteira do Brasil, Paraguai e Argentina. Recuperado de https://bityli.com/qLec9
Guimarães, D. S. (2013). Self and dialogical multiplication. Interacções, 9(24), 214-242. doi: 10.25755/int.2843

Guimarães, D. S. (2016). Descending and ascending trajectories of dialogical analysis: seventh analytic interpretation on the short story "The guerrillero". Psicologia USP, 27(2), 189-200. doi: 10.1590/0103-6564D20160003

Guimarães, D. S., Lima Neto, D. M., Soares, L. M., Santos, P. D., \& Carvalho, T. S. (2019). Temporalidade e corpo numa proposta de formação do psicólogo para o trabalho com povos indígenas. Psicologia: Ciência e Profissão, 39(spe), 147-158. doi: 10.1590/1982-3703003221929

Jensen, M., \& Guimarães, D. S. (2018). Expanding dialogical analysis across (sub-)cultural backgrounds. Culture \& Psychology, 24(4), 403-417. doi: 10.1177/1354067X18754340

Ladeira, M. I. (2007). O caminhar sob a luz o território Mbya à beira do oceano. São Paulo, SP: Unesp.

Langdon, E. (2005). Construção sociocultural da doença e seu desafio para a prática médica. In R. G. Baruzzi, \& C. Junqueira (Orgs). Parque indígena do Xingu: Saúde, cultura e história. São Paulo, SP: Terra Virgem.

Lei $n^{\circ}$ 9.836. (1999, 23 de setembro). Acrescenta dispositivos à Lei $\mathrm{n}^{\circ}$ 8.080, de 19 de setembro de 1990, que "dispõe sobre as condições para a promoção, proteção e recuperação da saúde, a organização e o funcionamento dos serviços correspondentes e dá outras providências", instituindo o Subsistema de Atenção à Saúde Indígena. Recuperado de https://bityli.com/eqLH8

Marin, N., \& Calabi, A. (Diretoras). (2012). Teko Rexaĩ: Saúde Guarani Mbyá (Documentário). Recuperado de https://bityli.com/MMBeI

Melià, B. (2010). (P. Fachin, Entrevistadora). A história de um guarani é a história de suas palavras. Revista do Instituto Humanitas Unisinos. Recuperado de https://bityli.com/HBhug

Melià, B. (2013). (K. Rattes, Entrevistador). Palavras ditas e escutadas. Entrevista. Mana, 19(1), 181-199. Recuperado de https://bityli.com/f5oxm

Ministério da Saúde. (2002, 31 de janeiro). Portaria $n^{\circ} 254$. Aprova a Política Nacional de Atenção à Saúde dos Povos Indígenas. Recuperado de https://bit.ly/3eZmvBu

OPAS/OMS apoia governos no objetivo de fortalecer e promover a saúde mental da população. (10 out. 2016). Recuperado de: https://bityli.com/tq3Fy

Pierri, D. C. (2013). O perecivel e o imperecível: lógica do sensivel e corporalidade no pensamento guarani-mbya. (Dissertação de Mestrado). Universidade de São Paulo, São Paulo. doi: 10.11606/D.8.2013.tde-06122013-122942 
Pissolato, E. (2007). A duração da pessoa. São Paulo, SP: Editora Unesp.

Sousa, F. R. (2018). Povos indígenas e saúde mental: a luta pelo habitar sereno e

confiado. (Dissertação de Mestrado). Universidade de São Paulo, São Paulo, SP. doi: 10.11606/D.47.2018.tde-19072018-102952

Simão, L. M. (2010). Ensaios dialógicos: Compartilhamento e diferença nas relações eu-outro. São Paulo: Hucitec.

Tajfel, H. (1984). Grupos Humanos y Categorias Sociales. Barcelona: Herder.

Turner, J. C., Oakes, P. J., Haslam, S. A., \& McGarty, C. (1994). Self and collective: Cognition and social context. Personality and Social Psychology Bulletin, 20(5),
Special issue: The self and the collective, 454-463. doi: $10.1177 / 0146167294205002$

Valsiner, J. (2019). Culture \& psychology: 25 Constructive years. Culture \& Psychology, 25(4), 429-469. doi: 10.1177/1354067X19872358

Bakhtin, M. (1997). Estética da criação verbal (2a ed.). São Paulo, SP: Martins Fontes.

Recebido: 10/04/2018

Revisado: 06/10/2019

Aprovado: 28/09/2020 